\title{
Glycyl-L-Glutamine Disposition in Rat Choroid Plexus Epithelial Cells in Primary Culture: Role of PEPT2
}

\author{
Yongjun Hu, ${ }^{1}$ Scott M. Ocheltree, ${ }^{1}$ Jianming Xiang, ${ }^{2}$ Richard F. Keep, ${ }^{2}$ and David E. Smith ${ }^{1,3,4}$
}

Received September 21, 2004; accepted March 11, 2005

Purpose. The purpose of this research was to determine the polarity and directionality of the PEPT2mediated uptake and transepithelial transport of the neuropeptide glycyl-L-glutamine (GlyGln) in choroid plexus.

Methods. The transport kinetics of $\left[{ }^{3} \mathrm{H}\right]$ GlyGln was studied in neonatal rat choroid plexus epithelial cells in primary culture grown on laminin-coated Transwell filter inserts. Using a bicarbonate artificial cerebrospinal fluid (CSF) buffer ( $\mathrm{pH} 7.4)$ at $37^{\circ} \mathrm{C}$, GlyGln studies were performed as a function of time, substrate concentration, and the presence of potential inhibitors (at $1 \mathrm{mM}$ ).

Results. GlyGln $(2 \mu \mathrm{M})$ accumulation was about three to four times greater when introduced from the apical (CSF-facing) as opposed to the basal (blood-facing) side of the cell monolayer, and transepithelial transport was about two times greater in the apical-to-basal direction. The apical uptake of radiolabeled GlyGln $(2 \mu \mathrm{M})$ was inhibited significantly by dipeptides (i.e., unlabeled GlyGln and cysteinylglycine) and some neuropeptides (i.e., carnosine, $N$-acetylaspartylglutamate, kyotorphin), but was unaffected by amino acids (i.e., glycine, glutamine) as well as by $\left[\mathrm{D}-\mathrm{Arg}^{2}\right]$-kyotorphin and glutathione. The concentration-dependent apical uptake of GlyGln $(2-1000 \mu \mathrm{M})$ was characterized by a high-affinity process (i.e., $\mathrm{V}_{\max }$ of $72 \mathrm{pmol} / \mathrm{mg} / \mathrm{min} ; \mathrm{K}_{\mathrm{m}}$ of $136 \mu \mathrm{M}$ ), consistent with the properties of PEPT2. The intracellular hydrolysis of GlyGln was extensive, however, with only $40 \%$ of the dipeptide remaining intact after $1 \mathrm{~h}$.

Conclusions. The results demonstrate that PEPT2 plays an important role in regulating the apical uptake of GlyGln at the blood-CSF interface. Once inside the cell, GlyGln is rapidly degraded to its constitutive amino acids for further processing.

KEY WORDS: choroid plexus; disposition; GlyGln; metabolism; PEPT2; transport; uptake.

\section{INTRODUCTION}

Glycyl-L-glutamine (GlyGln) is a biologically active neuropeptide that inhibits the firing frequencies of neurons in the nucleus reticularis gigantocellularis of rat brain stem $(1,2)$. It is also a potent inhibitor of the hypotension and respiratory depression produced by intracerebroventricular injection of morphine or $\beta$-endorphin in rats $(1,2)$. GlyGln is incapable of crossing the blood-brain barrier (3) but is, instead, formed within the brain as a result of the proteolytic

\footnotetext{
${ }^{1}$ Department of Pharmaceutical Sciences, The University of Michigan, Ann Arbor, Michigan 48109, USA

${ }^{2}$ Departments of Neurosurgery and Physiology, The University of Michigan, Ann Arbor, Michigan 48109, USA

${ }^{3}$ The University of Michigan, 4302A Upjohn Center, 1310 E. Catherine Street, Ann Arbor, Michigan 48109, USA

${ }^{4}$ To whom correspondence should be addressed. (e-mail: smithb@ umich.edu)
}

ABBREVIATIONS: BCSFB, blood-CSF barrier; CSF, cerebrospinal fluid; CysGly, cysteinylglycine; DKTP, [D-Arg $\left.{ }^{2}\right]$ kyotorphin; GlyGln, glycyl-L-glutamine; GlySar, glycylsarcosine; GSH, glutathione; HPLC, high-performance liquid chromatography; KTP, kyotorphin; NAAG, $N$-acetylaspartylglutamate; PEPT, peptide transporter; PHT, peptide/ histidine transporter. cleavage of $\beta$-endorphin (4). Thus, GlyGln exerts its biological activity as a metabolic fragment of polypeptide biotransformation. The process by which the neuropeptide activity of GlyGln is terminated, however, is unclear since clearance mechanisms from the brain, including the cerebrospinal fluid (CSF), are poorly understood for naturally occurring di- and tripeptide substrates.

The close proximity of aminopeptidases and peptide transporters (PEPTs) in the brain makes the coupling of peptide metabolism and transport an attractive combination. In this regard, a number of peptidases have been identified in the choroid plexus (5). Likewise, a high-affinity proton-coupled oligopeptide transporter, PEPT2, has been identified as being expressed and functionally active at the apical membrane of choroid plexus whole tissue (6-8) epithelial cells in primary culture (9) and native tissue (10). As a result, it is possible that GlyGln, once formed, can be cleared by PEPT2 into the choroid plexus, where it can then be transported into the blood, sequestered in the tissue itself, or broken down into its constituent amino acids for further use.

Few studies have examined the uptake and transepithelial transport mechanisms of di- and tripeptides in the choroid plexus. This is particularly true for biologically active peptides. While the neuropeptides $N$-acetylaspartylglutamate 
(NAAG), cysteinylglycine (CysGly), GlyGln, kyotorphin (KTP), and carnosine inhibited the PEPT2-mediated uptake of radiolabeled glycylsarcosine (GlySar) in isolated rat choroid plexus (8), the direct study of dipeptide disposition in choroid plexus and the role of PEPT2 in this process yielded conflicting results. In particular, the accumulation and transcellular transport of GlySar (a synthetic model dipeptide) were three to four times higher when introduced from the apical as opposed to basal side of rat choroid plexus epithelial cells in primary culture (9). Likewise, carnosine (a naturally occurring neurodipeptide) was preferentially taken up from the apical as opposed to basolateral membrane of epithelial cell monolayers (11). In contrast to GlySar, however, basolateral efflux was limited and, as a result, the transepithelial flux of carnosine was not distinguishable from that of paracellular diffusion alone. Instead, carnosine accumulated substantially within choroid plexus cells, achieving concentrations 135 times higher than that of the extracellular medium.

Given the limited understanding of how neuropeptides are handled at the blood-CSF interface, including peptide disposition once in the cell, the polarity and directionality of GlyGln uptake and transport were examined in rat choroid plexus primary cell cultures. Our results indicate that although PEPT2 facilitates the apical uptake of GlyGln into choroidal epithelial cells, this neuropeptide (in contrast to GlySar and carnosine) is rapidly metabolized to its constituent amino acids for further processing.

\section{MATERIALS AND METHODS}

All studies were carried out in accordance with the Guide for the Care and Use of Laboratory Animals as adopted and promulgated by the U.S. National Institutes of Health (NIH publication No. 85-23, revised in 1985).

\section{Materials}

$\left[{ }^{3} \mathrm{H}\right]$ GlyGln (10 Ci/mmol; radiochemical purity $97.7 \%$ ) was purchased from Moravek Biochemicals (Brea, CA) and $\left[{ }^{14} \mathrm{C}\right]$ mannitol $(53 \mathrm{mCi} / \mathrm{mmol})$ from American Radiolabeled Chemicals (St. Louis, MO). Unlabeled glycine and glutamine (i.e., amino acids), CysGly (i.e., dipeptide precursor of glutathione), and GlyGln, carnosine, NAAG, KTP, [D$\left.\mathrm{Arg}^{2}\right]$ kyotorphin (DKTP) and glutathione (GSH) (i.e., neuropeptides) were purchased from Sigma (St. Louis, MO). Other chemicals were obtained from standard sources and were of the highest quality available.

\section{Intracellular Accumulation and Transepithelial Transport of GlyGln in Cell Cultures}

Choroid plexus epithelial cells in primary culture were obtained from the lateral ventricles of 1- to 2-day-old Sprague-Dawley rats using the method of Strazielle and Ghersi-Egea (12). This method was validated and applied previously by our group in studying the uptake and transport kinetics of GlySar (9) and carnosine (11) at the blood-CSF barrier. In brief, choroid plexus cells were collected and seeded on laminin-coated Transwell-Clear filter inserts (12 mm diameter, $0.4 \mu \mathrm{m}$ pore size; Costar Plastics, Cambridge, MA). The culture medium was changed every $48 \mathrm{~h}$ after seeding and consisted of Dulbecco's minimum essential medium (DMEM)/F-12 (1:1) supplemented with 10\% (v/v) fetal bovine serum, $2 \mathrm{mM}$ glutamine, $25 \mu \mathrm{g} / \mathrm{ml}$ of gentamicin, $5 \mu \mathrm{g} / \mathrm{ml}$ of insulin, $5 \mu \mathrm{g} / \mathrm{ml}$ of transferrin, $5 \mathrm{ng} / \mathrm{ml}$ of sodium selenite, $10 \mathrm{ng} / \mathrm{ml}$ of epidermal growth factor, $2 \mu \mathrm{g} / \mathrm{ml}$ of hydrocortisone, and $5 \mathrm{ng} / \mathrm{ml}$ of basic fibroblast growth factor. Cells were grown in a sterile incubator at $37^{\circ} \mathrm{C}, 95 \%$ relative humidity, and $5 \% \mathrm{CO}_{2}$. Cultures were inspected visually for epithelial growth (i.e., cobblestone appearance) on a regular basis, and confluence occurred 5-7 days post-seeding. Transepithelial electrical resistance measurements were performed prior to experimentation (using a Millicell-ERS; Millipore Corp., Bedford, MA) as a measure of monolayer integrity. Values of $\geq 150 \mathrm{ohm} \cdot \mathrm{cm}^{2}$ were reached at 10-14 days postseeding, and were considered sufficient for experimentation.

Uptake and transport studies were performed in a bicarbonate artificial CSF buffer that consisted of (in $\mathrm{mM}): 127 \mathrm{NaCl}, 20 \quad \mathrm{NaHCO}_{3}, 2.4 \mathrm{KCl}, 0.5 \mathrm{KH}_{2} \mathrm{PO}_{4}, 1.1$ $\mathrm{CaCl}_{2}, 0.85 \mathrm{MgCl}_{2}, 0.5 \mathrm{Na}_{2} \mathrm{SO}_{4}$, and 5.0 glucose ( $\mathrm{pH} 7.4$ ), bubbled with $5 \% \mathrm{CO}_{2}$ and $95 \% \mathrm{O}_{2}$. Cell monolayers were preincubated apically $(0.4 \mathrm{ml})$ and basolaterally $(1.2 \mathrm{ml})$ with this buffer at $37^{\circ} \mathrm{C}$ for $10 \mathrm{~min}$. The buffer was removed and fresh buffer containing $\left[{ }^{3} \mathrm{H}\right]$ GlyGln and $\left[{ }^{14} \mathrm{C}\right]$ mannitol, with and without inhibitors, was added to the apical side $(0.4 \mathrm{ml})$ or basolateral side $(1.2 \mathrm{ml})$; control buffer (no isotope) was added to the opposite side. The cells were then incubated for the indicated period of time at $37^{\circ} \mathrm{C}$. To measure transepithelial transport, an aliquot $(100 \mu \mathrm{l})$ of the buffer was taken from the opposite side and the radioactivity was counted. To measure intracellular accumulation, the media were aspirated at the end of the incubation period and the monolayers rapidly washed four times on both sides with icecold buffer. The filters with monolayers were detached from the chambers and cells were solubilized in $0.5 \mathrm{ml}$ of $0.2 \mathrm{M}$ $\mathrm{NaOH}$ and $1 \%$ sodium dodecyl sulfate (SDS). The radioactivity of the collected buffer and of the solubilized cells was determined by liquid scintillation counting. The protein content of the solubilized cell monolayers was determined using a protein assay kit (Bio-Rad Laboratories, Hercules, CA) with bovine serum albumin as the standard.

GlyGln uptake data were corrected for filter binding and extracellular content, as described previously (7). The transepithelial transport of GlyGln was corrected for paracellular flux, as estimated by mannitol (9).

\section{Stability of GlyGIn}

The stability of GlyGln was evaluated in the apical, basolateral, and intracellular compartments of choroid plexus epithelial cells. Following the preparation of cell monolayers, as described previously, $2 \mu \mathrm{M}$ of $\left[{ }^{3} \mathrm{H}\right]$ GlyGln was incubated in the apical chamber for $5,15,30$, and $60 \mathrm{~min}$ at $37^{\circ} \mathrm{C}$. At the end of incubation, media from the apical and basolateral compartments were aspirated and saved for analysis. Cell monolayers were washed four times with ice-cold buffer, the filters detached, and $0.5 \mathrm{ml}$ of ice-cold Milli-Q water (Millipore Corp.) added prior to sonication for $10 \mathrm{~min}$. Cell lysates were then treated with an equal volume of acetonitrile, vortex-mixed for $5 \mathrm{~s}$, and centrifuged at 12,000 rpm 


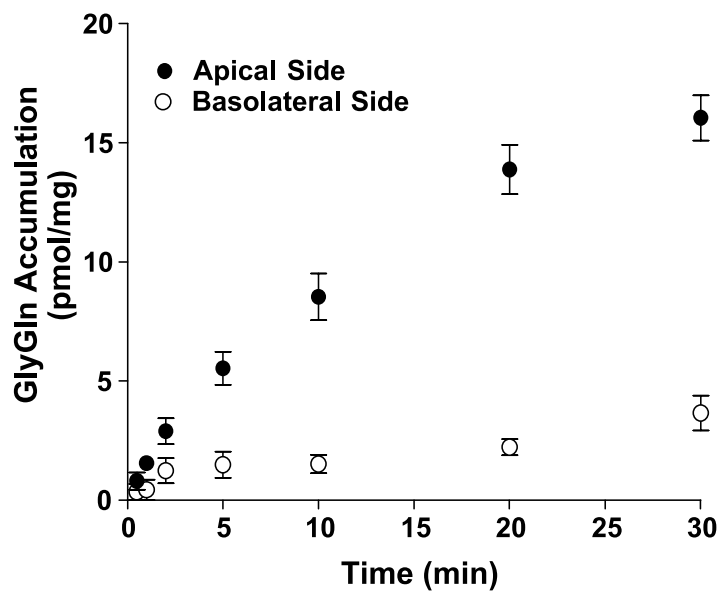

Fig. 1. Intracellular accumulation of GlyGln as a function of time in choroid plexus epithelial cells. Studies were performed with $2 \mu \mathrm{M}$ each of $\left[{ }^{3} \mathrm{H}\right]$ GlyGln $(0.04 \mu \mathrm{Ci})$ and $\left[{ }^{14} \mathrm{C}\right]$ mannitol $(0.02 \mu \mathrm{Ci}$; a marker for extracellular content) in bicarbonate artificial CSF buffer $(\mathrm{pH}$ $7.4)$ at $37^{\circ} \mathrm{C}$. Data are expressed as means \pm SE $(n=8)$. The apical uptake of GlyGln was significantly greater than basolateral uptake at all times, except at 0.5 and $1.0 \mathrm{~min}$.

for $5 \mathrm{~min}$ at $4^{\circ} \mathrm{C}$. The supernates were concentrated under cryo-vacuum (SpeedVac refrigerated concentrator; Savant Instruments Inc., Farmingdale, NY) and analyzed by highperformance liquid chromatography (HPLC). The stability of GlyGln was also evaluated in lysates prepared from choroid plexus whole tissue. For these preparations, 14-16 choroid plexuses were pooled from 7-8 neonatal rats and sonicated $(1$-s burst $\times 3)$ in ice-cold artificial CSF buffer. Tissue lysate (7.2 $\mathrm{mg}$ protein per $180 \mu \mathrm{l}$ of buffer) was preincubated for 5 min at $37^{\circ} \mathrm{C}$ and $\left[{ }^{3} \mathrm{H}\right]$ GlyGln added to the mixture. GlyGln was then incubated continuously in tissue lysate (at $\mathrm{pH} 7.4$ and $\mathrm{pH} 5.0)$ and samples $(25 \mu \mathrm{l})$ were obtained at 2, 5, 15, 30, and $60 \mathrm{~min}$ at $37^{\circ} \mathrm{C}$. Samples were then centrifuged at 12,000 rpm for $5 \mathrm{~min}$ at $4^{\circ} \mathrm{C}$ and analyzed by HPLC. GlyGln stability was determined by its recovery and by the appearance of glycine and glutamine following incubation.

Glycine, glutamine, and GlyGln were detected using an HPLC system consisting of a pump (Waters, Model 510, Milford, MA), a reversed-phase column (Hypersil ODS, C-18, $5 \mu \mathrm{m}, 250 \mathrm{~mm} \times 4.6 \mathrm{~mm}$, Alltech, Deerfield, IL) and a radiochromatography detector (FLO-ONE 500TR, Packard Instrument Co., Meriden, CT). The mobile phase was comprised of $0.01 \mathrm{M}$ phosphate buffer $(\mathrm{pH} 2.0)$ and $0.1 \%$ heptafluorobutyric acid, and pumped isocratically at $1 \mathrm{ml} / \mathrm{min}$. Retention times for glycine, glutamine, and GlyGln were 4.07, 4.23, and $9.30 \mathrm{~min}$, respectively, under ambient conditions. Peaks were identified by injecting known standards of radiolabeled glycine, glutamine, and GlyGln (Moravek Biochemicals).

\section{Data Analysis}

For kinetic studies, the concentration-dependent uptake of GlyGln was best fit to a Michaelis-Menten relationship such that: $\mathrm{V}=\mathrm{V}_{\max } \cdot \mathrm{S} /\left(\mathrm{K}_{\mathrm{m}}+\mathrm{S}\right)$, where $\mathrm{V}_{\max }$ is the maximal rate of saturable uptake, $K_{m}$ is the Michaelis constant, and $S$ is the substrate concentration. To evaluate if more than one class of transporters was operational for GlyGln uptake, a Woolf-Augustinsson-Hofstee transformation was performed on the saturable component where: $\mathrm{V}=\mathrm{V}_{\max }-\mathrm{K}_{\mathrm{m}}(\mathrm{V} / \mathrm{S})$.

Data are reported as means $\pm \mathrm{SE}$ (unless otherwise indicated), with data from each experiment determined in duplicate or triplicate. Statistical comparisons were performed with ANOVA (GraphPad Prism, v3.0; GraphPad Software, Inc., San Diego, CA) and post hoc pairwise comparisons made with Dunnett's test. A probability of $\mathrm{p} \leq$ 0.05 was considered statistically significant. Linear and nonlinear regression analyses were performed with SigmaPlot 8.0 (SPSS Inc., Chicago, IL) and a weighting factor of unity. The quality of fit was determined by evaluating the coefficient of determination $\left(\mathrm{r}^{2}\right)$, the coefficient of variation $(\mathrm{CV} \%)$ of parameter estimates, and by visual inspection of the residuals.

\section{RESULTS AND DISCUSSION}

\section{Time Course of GlyGin Accumulation and Transepithelial Transport}

As shown in Fig. 1, the uptake of GlyGln was substantially greater when introduced from the apical than from the basolateral surface of the cell monolayers (i.e., about three to four times). Similarly, the apical-to-basolateral flux of GlyGln was greater than that of GlyGln in the reverse direction (i.e., about two times) (Fig. 2). Given the strong preference of GlyGln for apical uptake, along with PEPT2 being localized to the apical surface of choroid plexus epithelial cells, the kinetic properties $\left(\mathrm{V}_{\max }, \mathrm{K}_{\mathrm{m}}\right)$ and specificity ( \pm potential inhibitors) of GlyGln were further characterized at this membrane surface alone. For these analyses, initial rates were determined at 2 min, a time in which GlySar was still in the linear region of uptake.

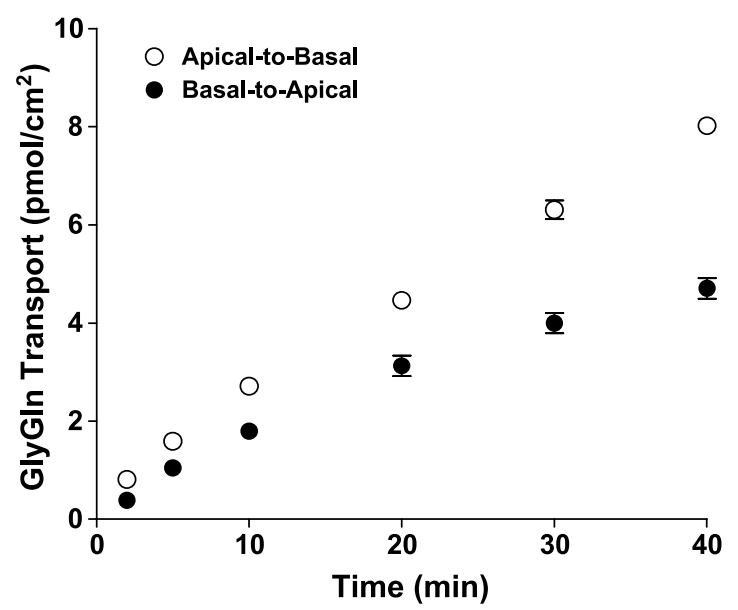

Fig. 2. Transepithelial transport of GlyGln as a function of time in choroid plexus epithelial cells. Studies were performed with $2 \mu \mathrm{M}$ each of $\left[{ }^{3} \mathrm{H}\right]$ GlyGln $(0.04 \mu \mathrm{Ci})$ and $\left[{ }^{14} \mathrm{C}\right]$ mannitol $(0.02 \mu \mathrm{Ci}$; a marker for paracellular transport) in bicarbonate artificial CSF buffer $(\mathrm{pH}$ $7.4)$ at $37^{\circ} \mathrm{C}$. Data are expressed as means \pm SE $(n=16)$. The apicalto-basolateral transport of GlyGln was significantly greater than basolateral-to-apical transport at all times, except at $2.0 \mathrm{~min}$. 


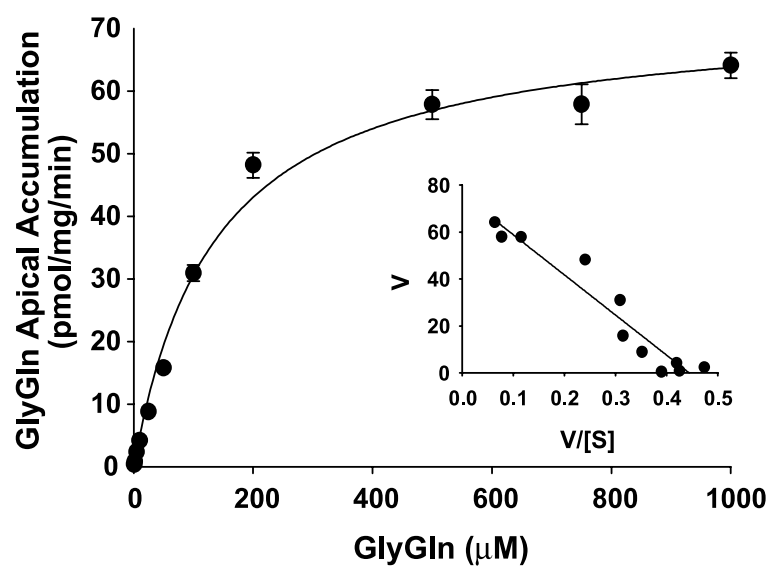

Fig. 3. Concentration-dependent uptake of GlyGln in choroid plexus epithelial cells. The 2-min apical uptake of $\left[{ }^{3} \mathrm{H}\right] \mathrm{GlyG} \ln (0.04-1.2 \mu \mathrm{Ci}$; $2-1000 \mu \mathrm{M}$ total drug) was evaluated in bicarbonate artificial CSF buffer $(\mathrm{pH} 7.4)$ at $37^{\circ} \mathrm{C} ;\left[{ }^{14} \mathrm{C}\right]$ mannitol $(0.02-0.4 \mu \mathrm{Ci} ; 2 \mu \mathrm{M}$ total compound) was also present as a marker for extracellular content. The experimental data are expressed as means $\pm \operatorname{SE}(n=4-8)$. The predicted curve was generated using the mean parameters for $\mathrm{V}_{\max }$ and $\mathrm{K}_{\mathrm{m}}$, as determined by nonlinear regression $\left(\mathrm{r}^{2}=0.991\right)$ and reported in the text. The inset is a Woolf-Augustinsson-Hofstee plot of the transformed data [uptake $(\mathrm{V}), \mathrm{pmol} / \mathrm{mg} / \mathrm{min} v s$. uptake per concentration $(\mathrm{V} /[\mathrm{S}], \mu \mathrm{l} / \mathrm{mg} / \mathrm{min}]$, which is linear $\left(\mathrm{r}^{2}=0.926\right)$. Error bars are omitted in the inset for clarity.

\section{Concentration-Dependent Apical Uptake of GlyGIn}

The apical uptake of GlyGln was probed over a buffer concentration range of $2-1000 \mu \mathrm{M}$. As shown in Fig. 3, GlyGln was taken up by choroid plexus epithelial cells in a concentration-dependent manner with a $\mathrm{V}_{\max }$ of $72.5 \pm 2.7$ $\mathrm{pmol} / \mathrm{mg} / \mathrm{min}$ and $\mathrm{a} \mathrm{K}_{\mathrm{m}}$ of $137 \pm 18 \mu \mathrm{M}\left(\mathrm{r}^{2}=0.991\right)$. Only one transport system was involved in the apical uptake of GlyGln, as suggested by the single linear slope during

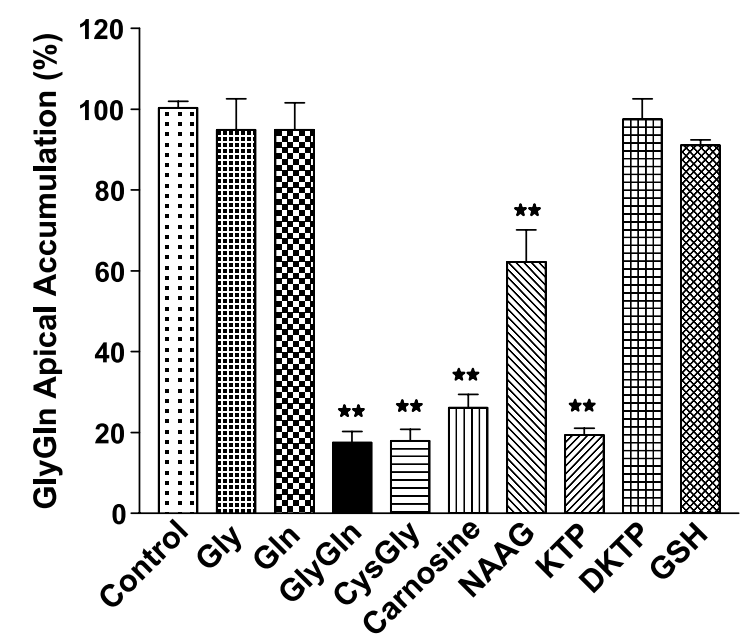

Fig. 4. Effect of potential inhibitors on the apical uptake of GlyGln in choroid plexus epithelial cells. The 2-min apical uptake of $2 \mu \mathrm{M}$ $\left[{ }^{3} \mathrm{H}\right]$ GlyGln $(0.04 \mu \mathrm{Ci})$ was evaluated in bicarbonate artificial CSF buffer $(\mathrm{pH} 7.4)$ at $37^{\circ} \mathrm{C} ; 2 \mu \mathrm{M}\left[{ }^{14} \mathrm{C}\right]$ mannitol $(0.02 \mu \mathrm{Ci})$ was also present as a marker for extracellular content. The experimental data are expressed as mean $\pm \mathrm{SE}(n=4-9)$. ** $p<0.01$ as compared to control values. a Woolf-Augustinsson-Hofstee transformation of the data (see insert, $\mathrm{r}^{2}=0.926$ ). These values are consistent with that of PEPT2 in choroid plexus whole tissue (i.e., high-affinity interactions with $\mathrm{K}_{\mathrm{m}}$ values of $39-260 \mu \mathrm{M}$ for peptides/ mimetics) (5) and, in particular, with that of GlySar (i.e., $\mathrm{V}_{\max }$ of $31 \mathrm{pmol} / \mathrm{mg} / \mathrm{min}, \mathrm{K}_{\mathrm{m}}$ of $60 \mu \mathrm{M}$ ) (9) and carnosine (i.e., $\mathrm{V}_{\max }$ of $73 \mathrm{pmol} / \mathrm{mg} / \mathrm{min}, \mathrm{K}_{\mathrm{m}}$ of $34 \mu \mathrm{M}$ ) (11) in choroid plexus primary cell cultures.

\section{Specificity of Apical Uptake for GlyGln}

The specificity of GlyGln's apical uptake was probed using a wide range of potential amino acid, dipeptide, and neuropeptide inhibitors (Fig. 4). The constitutive amino acids of GlyGln were without effect, confirming the stability of GlyGln during the incubation process. As expected, GlyGln

A

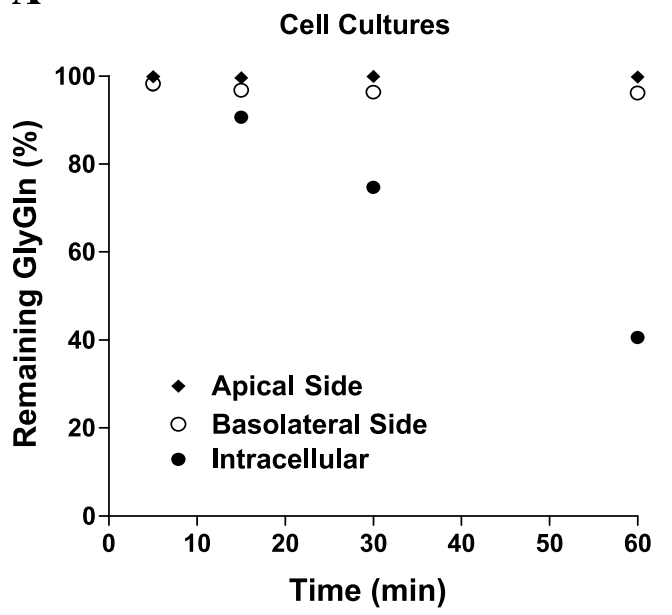

B

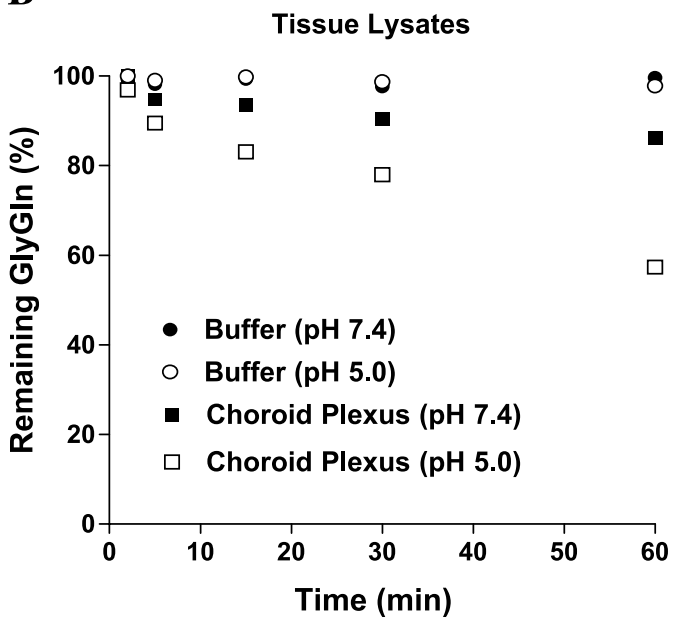

Fig. 5. (A) GlyGln stability as a function of time in choroid plexus epithelial cells. Studies were performed in bicarbonate artificial CSF buffer ( $\mathrm{pH} 7.4)$ at $37^{\circ} \mathrm{C}$ in which monolayers were incubated apically with $2 \mu \mathrm{M}$ of $\left[{ }^{3} \mathrm{H}\right] \mathrm{GlyG}$. Stability was assessed in the apical and basolateral chambers, and in the intracellular compartment. Data are expressed as the mean of two experiments $(\leq 10 \%$ difference between studies). (B) GlyGln stability as a function of time in choroid plexus whole tissue lysates ( $\mathrm{pH} 7.4$ and $\mathrm{pH}$ 5.0). Data are expressed as the means of two preparations (with each preparation containing 14-16 choroid plexuses from 7-8 animals). Control studies were also performed in buffer alone ( $\mathrm{pH} 7.4$ and $\mathrm{pH} 5.0)$. 
exhibited self-inhibition (i.e., reduced accumulation of radiolabel in the presence of unlabeled dipeptide) along with inhibition by the dipeptide CysGly (about $80-85 \%$ ). With respect to neuropeptides, GlyGln was inhibited by carnosine (74\%), NAAG $(38 \%)$, and KTP $(81 \%)$, but was not inhibited by DKTP or GSH. Thus, it appears that the apical uptake of GlyGln into choroid plexus cells may be influenced by dipeptide fragments and/or neuropeptides that share the same pharmacophore for PEPT2. For example, DKTP (L-Tyr-D-Arg) is a stereoisomer of KTP (L-Tyr-L-Arg) in which the L-configuration is preferred for transport. Likewise, free amino acids that are one (i.e., $\alpha$-position) or at most two (i.e., $\beta$-position) methylene groups from the backbone carbonyl group have been demonstrated to exhibit a high-affinity transport by PEPT2 (13). GSH, with a free amino acid in the $\gamma$-position would, therefore, have a much reduced or nonexistent uptake.

\section{Stability of GlyGIn}

For those primary cell culture studies in which 2-min uptakes were determined (i.e., kinetic and inhibition experiments), GlyGln was found to be stable during the incubation period. As shown in Fig. 5A, 99.8\% and 96.2\% of the label remained intact in the apical and basolateral compartments, respectively, at $60 \mathrm{~min}$. In contrast, the intracellular compartment retained $97.9 \%$ of the intact label at $5 \mathrm{~min}, 90.6 \%$ at $15 \mathrm{~min}, 74.7 \%$ at $30 \mathrm{~min}$, and only $40.6 \%$ after $60 \mathrm{~min}$ of incubation. Given the substantial metabolism of GlyGln at 60 min, yet the insignificant amount of degradation product found in apical or basolateral chambers, it appears that the constituent amino acids remain in the cell for further processing. To further understand the intracellular degradation of GlyGln, additional experiments were performed in lysates prepared from choroid plexus whole tissue. As shown in Fig. $5 \mathrm{~B}$, only about $15 \%$ of the drug was metabolized in $\mathrm{pH} 7.4$ tissue lysate after $60 \mathrm{~min}$ of incubation, whereas about $43 \%$ of GlyGln was metabolized in $\mathrm{pH} 5.0$ tissue lysate over the same time period. In contrast, control experiments (GlyGln added to buffer) showed no degradation of GlyGln as a function of $\mathrm{pH}$ alone. These results suggest that GlyGln may be preferentially metabolized in lysosomes, where a $\mathrm{pH}$ of about 5.0 in its interior is optimal for the activity of hydrolytic enzymes (14).

PEPT2 is a member of the proton-coupled oligopeptide transporter family along with PEPT1 and the peptide/histidine transporters (PHTs) PHT1 and PHT2 (15-18). Immunolocalization studies $(9,10)$ have confirmed that whereas PEPT2 protein is expressed widely throughout the brain, including the apical membrane of choroid plexus, PEPT1 protein is absent in this tissue. Functional studies, using inhibition of radiolabeled dipeptide by excess L-histidine, have consistently failed to support a role for the peptide/ histidine transporters, PHT1 and PHT2, at the plasma membrane of choroid plexus tissue (6-8) and primary cell cultures $(9,11)$. Moreover, studies in wild type and PEPT2 null mice have clearly demonstrated that PEPT2 is responsible for about $80-95 \%$ of the uptake of GlySar $(19,20)$, 5-aminolevulinic acid (20), carnosine (11), and cefadroxil (21) in choroid plexus whole tissue. Despite our current understanding that PEPT2 plays a predominant role in the choroid plexus uptake of peptides/mimetics and peptide-like drugs, the disposition of specific neuropeptides, as opposed to model synthetic dipeptide probes, at the blood-CSF barrier (BCSFB) is still uncertain.

In the present study, we studied the uptake, transepithelial transport, and cellular metabolism of GlyGln, a dipeptide fragment of $\beta$-endorphin proteolysis, in choroid plexus epithelial cells in primary culture. We found that GlyGln is preferentially taken up and transported across choroid plexus epithelium by a PEPT2-mediated process at the apical surface of the cell membrane. We also found that GlyGln is rapidly degraded intracellularly, probably by lysosomes, into its constitutive amino acids. The ability to provide free glycine and glutamine for utilization by the cellular machinery might have significant value. In this context, glycine could combine with GluCys to form the antioxidant glutathione (22), and glutamine could be used in protein synthesis, as a nitrogen donor for the synthesis of purines, pyrimidines, nucleotides, and amino sugars, and in the regulation of acid-base balance (23). The importance of GlyGln as a source of free amino acids for these potential functions needs to be determined, however. Taken as a whole, PEPT2 serves as a conduit for a wide range of di- and tripeptides, neuropeptides, and peptide-like drugs to access the choroid plexus cell from the CSF. The disposition of these substrates, however, may vary once in the cell. While some peptides may be effluxed into the blood, as found for the hydrolysis- and peptidase-resistant dipeptide GlySar (9), others may accumulate in the choroid plexus, as observed for carnosine (11). In contrast, GlyGln is metabolized intracellularly by the choroid plexus, where it can then be recycled.

\section{ACKNOWLEDGMENTS}

This work was supported in part by Grants R01GM035498 (D.E.S.), R01NS034709 and P01HL018575 (R.F.K.). Scott M. Ocheltree was supported by an AFPE Pre-Doctoral Fellowship and the Pharmacological Sciences Training Program of the National Institutes of Health (GM07767).

\section{REFERENCES}

1. C. B. Unal, M. D. Owen, and W. R. Millington. Cyclo(Gly-Gln) inhibits the cardiorespiratory depression produced by $\beta$-endorphin and morphine. Brain Res. 747:52-59 (1997).

2. M. D. Owen, C. B. Unal, M. F. Callahan, K. Trivedi, C. York, and W. R. Millington. Glycyl-glutamine inhibits the respiratory depression, but not the antinociception, produced by morphine. Am. J. Physiol. 279:R1944-R1948 (2000).

3. J. A. Vazquez, M. Raghunath, and S. A. Adibi. Uptake and hydrolysis of glycylglutamine at the blood-brain barrier. Metabolism 41:121-124 (1992).

4. D. C. Parish, D. G. Smyth, J. R. Normanton, and J. H Wolstencroft. Glycyl glutamine, an inhibitory neuropeptide derived from $\beta$-endorphin. Nature 306:267-270 (1983).

5. D. E. Smith, C. E. Johanson, and R. F. Keep. Peptide and peptide analog transport systems at the blood-CSF barrier. $A d v$. Drug Deliv. Rev. 56:1765-1791 (2004).

6. A. Novotny, J. Xiang, W. Stummer, N. S. Teuscher, D. E. Smith, and R. F. Keep. Mechanisms of 5-aminolevulinic acid uptake at the choroid plexus. J. Neurochem. 75:321-328 (2000). 
7. N. S. Teuscher, A. Novotny, R. F. Keep, and D. E. Smith Functional evidence for the presence of PEPT2 in rat choroid plexus: Studies with glycylsarcosine. J. Pharmacol. Exp. Ther. 294:494-499 (2000).

8. N. S. Teuscher, R. F. Keep, and D. E. Smith. PEPT2-mediated uptake of neuropeptides in rat choroid plexus. Pharm. Res. 18:807-813 (2001).

9. C. Shu, H. Shen, N. S. Teuscher, P. J. Lorenzi, R. F. Keep, and D. E. Smith. Role of PEPT2 in peptide/mimetic trafficking at the blood-cerebrospinal fluid barrier: Studies in rat choroid plexus epithelial cells in primary culture. J. Pharmacol. Exp. Ther. 301:820-829 (2002).

10. H. Shen, D. E. Smith, R. F. Keep, and F. C. Brosius III Immunolocalization of the proton-coupled oligopeptide transporter PEPT2 in developing rat brain. Mol. Pharm. 1:248-256 (2004).

11. N. S. Teuscher, H. Shen, C. Shu, J. Xiang, R. F. Keep, and D. E. Smith. Carnosine uptake in rat choroid plexus primary cell cultures and choroid plexus whole tissue from PEPT2 null mice. J. Neurochem. 89:375-382 (2004).

12. N. Strazielle and J.-F. Ghersi-Egea. Demonstration of a coupled metabolism-efflux process at the choroid plexus as a mechanism of brain protection toward xenobiotics. J. Neurosci. 19:62756289 (1999).

13. S. Theis, B. Hartrodt, G. Kottra, K. Neubert, and H. Daniel. Defining minimal structural features in substrates of the $\mathrm{H}+/$ peptide cotransporter PEPT2 using novel amino acid and dipeptide derivatives. Mol. Pharmacol. 61:214-221 (2002).

14. B. Alberts, D. Bray, J. Lewis, M. Raff, K. Roberts, and J. D. Watson. Molecular Biology of the Cell, 3rd ed., Garland Publishing Inc., New York, 1994, pp. 610-611.
15. H. Daniel and G. Kottra. The proton oligopeptide cotransporter family SLC15 in physiology and pharmacology. Pflugers Arch. 447:610-618 (2004)

16. D. Herrera-Ruiz and G. T. Knipp. Current perspectives on established and putative mammalian oligopeptide transporters. J. Pharm. Sci. 92:691-714 (2003).

17. I. Rubio-Aliaga and H. Daniel. Mammalian peptide transporters as targets for drug delivery. Trends in Pharmacol. Sci. 23: 434-440 (2002).

18. H. Daniel and I. Rubio-Aliaga. An update on renal peptide transporters. Am. J. Physiol. 284:F885-F892 (2003).

19. H. Shen, D. E. Smith, R. F. Keep, J. Xiang, and F. C. Brosius III. Targeted disruption of the PEPT2 gene markedly reduces dipeptide uptake in choroid plexus. J. Biol. Chem. 278:4786-4791 (2003).

20. S. M. Ocheltree, H. Shen, Y. Hu, J. Xiang, R. F. Keep, and D. E. Smith. Role of PEPT2 in the choroid plexus uptake of glycylsarcosine and 5-aminolevulinic acid: studies in wild-type and null mice. Pharm. Res. 21:1680-1685 (2004).

21. S. M. Ocheltree, H. Shen, Y. Hu, J. Xiang, R. F. Keep, and D. E. Smith. Mechanisms of cefadroxil uptake in the choroid plexus: studies in wild-type and PEPT2 knockout mice. J. Pharm. Exp. Ther. 308:462-467 (2004).

22. R. Dringen, B. Pfeiffer, and B. Hamprecht. Synthesis of the antioxidant glutathione in neurons: supply by astrocytes of CysGly as precursor for neuronal glutathione. J. Neurosci. 19:562-569 (1999).

23. P. Fürst and P. Stehle. Glutamine and glutamine-containing dipeptides. In L. A. Cynober (ed.), Metabolic and Therapeutic Aspects of Amino Acids in Clinical Nutrition, 2nd ed. CRC Press, Boca Raton, FL, 2004, pp. 613-631. 